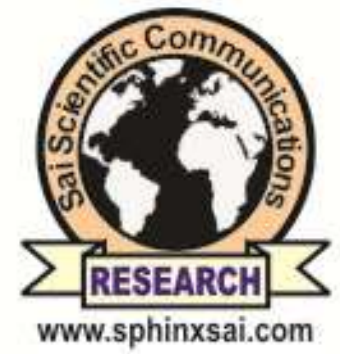

International Journal of PharmTech Research CODEN (USA): IJPRIF, ISSN: 0974-4304, ISSN(Online): 2455-9563

Vol.13, No.01, pp 20-25,

2020

\title{
Comparison of Post-Operative Clinical Outcome of Patients with PosteriorInstrumentation After Spinal Cord Injury in Thoracic, Thoracolumbar, and Lumbar Region at Haji Adam Malik General Hospital, Medan from 2016 to 2018
}

\author{
Budi Achmad M. Siregar ${ }^{1 *}$, Pranajaya Dharma Kadar², \\ Aga Shahri Putera Ketaren ${ }^{3}$
}

\begin{abstract}
${ }^{1}$ Resident of Orthopaedic and Traumatology, Faculty of Medicine, University of Sumatera Utara / Haji Adam Malik General Hospital, Medan, Indonesia ${ }^{2}$ Consultant Orthopaedic and Traumatology, Spine Division, Faculty of Medicine, University of Sumatera Utara / Haji Adam Malik General Hospital, Medan, Indonesia ${ }^{3}$ Consultant Orthopaedic and Traumatology, Upper Extremity Division,Faculty of Medicine, University of Sumatera Utara / Haji Adam MalikGeneral Hospital, Medan , Indonesia
\end{abstract}

\begin{abstract}
Introduction : Spinal cord injury is a damaging situation related to severe disability and death after trauma.And the term spinal cord injury refers to damage of the spinal cord resulting from trauma. Spinal injuries treatment is still in debate for some cases, whether using conservative or surgical methods.

Material and Methods : The study was a retrospective, unpaired observational analytic study with a crosssectional approach. It was conducted at Haji Adam Malik General Hospital, Medan from January 2016 to December 2018. Clinical outcome of patientswere calculated using SF 36, ODI, and VAS.Data would be tested using the Saphiro-Wilk test. We were using the significance level of $1 \%(0.01)$ and the relative significance level of $10 \%(0.1)$.

Results : Clinical outcomes of patients with spinal cord injuries before posterior instrumentation rated using ODI and VAS were $75.93 \pm 6.75$ and 4.75 \pm 0.98 respectively. Meanwhile, the scores were 10.75 \pm 3.29 (ODI) and $1.77 \pm 0.72$ (VAS) post-operatively. Using SF-36, the scores were

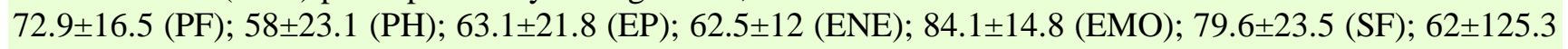
(PAIN); 49.5 $\pm 3.4(\mathrm{GH})$; and $72 \pm 7.8(\mathrm{HC})$ pre-operatively. After posterior instrumentation, the scores were

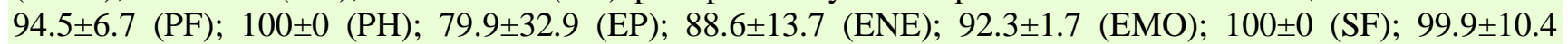
(PAIN); $89.3 \pm 14.9(\mathrm{GH})$; and 92.4 \pm 9.7 (HC). Discussion : In this study, patients with thoracal, thoracolumbar and lumbar injuries who underwent surgery experienced significant improvements in quality of life. This is indicated by the significant difference in ODI, VAS, and SF-36 scores before and after surgery. The results of this study were consistent with other studies conducted by Hao et al, which showed that there was an improvement in the quality of life of patients after surgery. Conclusion : There are significant improvements in patient's quality of life after posterior instrumentation of the spinal cord injury in thoracal, thoracolumbar, and lumbar regions based on the clinical outcomes.

Keywords : clinical outcome; posterior instrumentation; spinal cord injury; ODI; SF-36; VAS.
\end{abstract}

Budi Achmad M. Siregar et al /International Journal of PharmTech Research, 2020,13(1): 20-25.

DOI= http://dx.doi.org/10.20902/lJPTR.2019.130103 


\section{Introduction}

Spinal cord injury is a damaging situation related to severe disability and death after trauma. And the term spinal cord injury refers to damage of the spinal cord resulting from trauma. ${ }^{1,2,3}$

Symptoms of spinal cord injury depend on the severity of the injury and its location in the spinal cord. ${ }^{4,5}$ Symptoms can include partial or complete loss of sensory function or motoric control of the arm, leg, and body. ${ }^{6}$ The most severe spinal cord injuries affect the system that regulates bowel or bladder control, breathing, heart rate and blood pressure. ${ }^{7,8}$ Most people with spinal injuries suffer from chronic pain and result in decreased quality of life, the doctor's decision to perform a surgery, greatly affects the quality of life of a patient. ${ }^{9,10}$

In its report in 2013, WHO stated that there was no estimate of global prevalence that could be a reference data for spinal injury, but the estimated annual global incidence was 40 to 80 cases per million population. ${ }^{11}$ Up to $90 \%$ of cases of spinal cord injury are caused by trauma. People with spinal injuries are 2 to 5 times more likely to die prematurely. ${ }^{12,13,14}$

Spinal injury is associated with the risk of severe and life-threatening conditions such as DVT (deep vein thrombosis), urinary tract infections, osteoporosis, muscle spasms, pressure sores, chronic pain, and respiratory complications. ${ }^{15,16,17}$ Acute care, rehabilitation, and ongoing health care are very important for the prevention and management of this condition, but several studies conclude that the management of spinal injuries is still needed in patients with thoracic, thoracolumbar, and lumbar injuries. ${ }^{1,18}$ Spinal injuries treatment is still in debate for some cases, whether using conservative or surgical methods. ${ }^{2}$ Thoracal, thoracolumbar, and lumbar fractures are often associated with neurological dysfunction. ${ }^{19,20}$

Based on the description above and because data of patients with spinal cord injuries and clinical outcomes of patients with spinal cord injuries in the thoracal, thoracolumbar, and lumbar regions undergoing posterior instrumentation surgery in Medan are not available, we are very interested in comparing clinical outcomes after spinal injury instrumentation,particularly in the thoracolumbal region at the Haji Adam Malik General Hospital in Medan.

\section{Materials and Methods}

The study was a retrospective, unpaired observational analytic study with a cross-sectional approach. All patients with spinal cord injuries in thoracal, thoracolumbar, and lumbar region and who have signed the informed consent form were included in this study. We excluded patients with degenerative spine disease and spinal infection. The study was conducted at Haji Adam Malik General Hospital, Medan from 2016 to 2018.

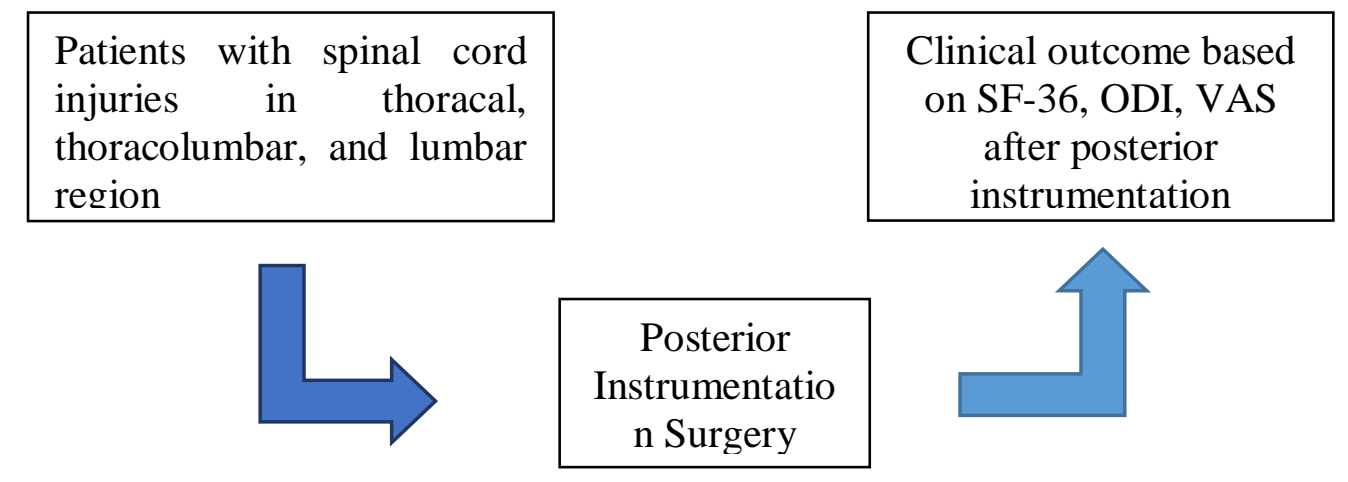

Figure 1. Research Flow

Study samples were obtained from primary patient data from January 2016 to December 2018. Clinical outcome of patients included in the inclusion criteria were calculated using SF 36, ODI, and VAS.Data would be tested for normality using the Saphiro-Wilk test. If the data distribution was normal, the paired T-test would be used. But if the distribution of the data is not normal, the analysis used would be the Wilcoxon test. We were using the significance level of $1 \%(0.01)$ and the relative significance level of $10 \%(0.1)$. A difference would be considered significant if the $\mathrm{p}$-value $<0.05$. 


\section{Results}

\section{Characteristics}

Table 1 shown that the distribution from 48 samples underwent posterior instrumentation was 24 women (50\%) and 24 men (50\%). The youngest age of the study subjects was 13 years old, the oldest age of the study subjects was 88 years old with an average age of 48.94 years old with a standard deviation of 18.49 SD.

Table 1. Distribution of Demographic Characteristics

\begin{tabular}{|l|l|}
\hline Variables & Total \\
\hline Female (\%) & $24(50 \%)$ \\
\hline Male (\%) & $24(50 \%)$ \\
\hline Min & 13 years old \\
\hline Max & 88 years old \\
\hline Median & 48,94 years old \\
\hline StandardDeviation & 18,49 SD \\
\hline
\end{tabular}

Table 2. Description of the Clinical Outcomes of Patients with Spinal Cord Injuries Before and After Posterior Instrumentation; ODI = Oswestry Disability Index; VAS = Visual Analog Scale; PF = Physical Functioning; $\mathbf{P H}=$ Physical Health; $\mathbf{E P}=$ Emotional Problem; ENE = Energy $/$ Fatigue $;$ EMO = Emotional Well Being; SF = Social Functioning;GH= General Health;HC = Health Change

\begin{tabular}{|c|c|c|c|c|c|c|c|c|c|c|c|}
\hline \multirow{3}{*}{ Variables } & \multicolumn{11}{|c|}{ Clinical Outcomes } \\
\hline & \multirow{2}{*}{ ODI } & \multirow{2}{*}{ VAS } & \multicolumn{9}{|l|}{ SF 36} \\
\hline & & & $\mathrm{PF}$ & $\mathrm{PH}$ & EP & ENE & EMO & SF & PAIN & GH & $\mathrm{HC}$ \\
\hline Pre-operative & $\begin{array}{l}75,93 \pm \\
6,75\end{array}$ & $\begin{array}{l}4,75 \pm \\
0,98\end{array}$ & $\begin{array}{l}72,9 \pm 1 \\
6,5\end{array}$ & $\begin{array}{l}58 \pm 2 \\
3,1\end{array}$ & $\begin{array}{l}63,1 \pm 2 \\
1,8\end{array}$ & $\begin{array}{l}62,5 \pm 1 \\
2,0\end{array}$ & $\begin{array}{l}84,1 \pm 1 \\
4,8\end{array}$ & $\begin{array}{l}79,6 \pm 2 \\
3,5\end{array}$ & $\begin{array}{l}62,0 \pm 1 \\
25,3\end{array}$ & $\begin{array}{l}49,5 \pm \\
3,4\end{array}$ & $\begin{array}{l}72,0 \pm \\
7,8\end{array}$ \\
\hline Post-operative & $\begin{array}{l}10,75 \pm \\
3,29 \\
\end{array}$ & $\begin{array}{l}1,77 \pm \\
0,72\end{array}$ & $\begin{array}{l}94,5, \pm \\
6,7 \\
\end{array}$ & $\begin{array}{l}100,0 \\
\pm 0\end{array}$ & $\begin{array}{l}79,9 \pm 3 \\
2,9\end{array}$ & $\begin{array}{l}88,6 \pm 1 \\
3,7\end{array}$ & $\begin{array}{l}92,3 \pm 1 \\
, 7 \\
\end{array}$ & $\begin{array}{l}100,0 \pm \\
0,0\end{array}$ & $\begin{array}{l}99,9 \pm 1 \\
0,4\end{array}$ & $\begin{array}{l}89,3 \pm \\
14,9 \\
\end{array}$ & $\begin{array}{l}92,4 \pm \\
9,7\end{array}$ \\
\hline p-Value & 0,001 & 0,001 & 0,001 & 0,001 & 0,010 & 0,001 & 0,047 & 0,002 & 0,001 & 0,001 & 0,001 \\
\hline
\end{tabular}

\section{Clinical Outcome (ODI, VAS, SF-36)}

Table 2 explained that clinical outcomes of patients with spinal cord injuries before posterior instrumentation rated using ODI and VAS were $75.93 \pm 6.75$ and $4.75 \pm 0.98$ respectively. Meanwhile, the scores were 10.75 \pm 3.29 (ODI) and 1.77 \pm 0.72 (VAS) post-operatively. The p-value for both ODI and VAS was 0.001 .

Clinical outcomes of patients with spinal cord injuries before posterior instrumentation rated using SF36 were divided into several categories. The scores were $72.9 \pm 16.5(\mathrm{PF}) ; 58 \pm 23.1(\mathrm{PH}) ; 63.1 \pm 21.8(\mathrm{EP})$; 62.5 \pm 12 (ENE); $84.1 \pm 14.8$ (EMO); 79.6 \pm 23.5 (SF); 62 \pm 125.3 (PAIN); 49.5 $\pm 3.4(\mathrm{GH})$; and 72 \pm 7.8 (HC) preoperatively. After posterior instrumentation, the scores were 94.5 \pm 6.7 (PF); $100 \pm 0(\mathrm{PH}) ; 79.9 \pm 32.9$ (EP); 88.6 \pm 13.7 (ENE); 92.3 \pm 1.7 (EMO); $100 \pm 0$ (SF); 99.9 \pm 10.4 (PAIN); $89.3 \pm 14.9$ (GH); and 92.4 \pm 9.7 (HC). The p-value for PF, PH, ENE, PAIN, GH, and HC was 0.001. While for EP, EMO, and SF were 0.01; 0.047; and 0.002 respectively.

Table 3. Description of Clinical Outcomes of Subjects with Spinal Cord Injuries of the Thoracic, Thoracolumbar, and Lumbar Regions Before and After Posterior Instrumentation According to Frankle

\begin{tabular}{|l|l|l|}
\hline Frankle & n (\%) Pre-operatively & $\mathbf{n}(\%)$ Post-operatively \\
\hline A & $6(12,5 \%)$ & $3(6,2 \%)$ \\
\hline B & $6(12,5 \%)$ & $3(6,2 \%)$ \\
\hline C & $11(22,9 \%)$ & $4(8,3 \%)$ \\
\hline D & $15(31,3 \%)$ & $13(34,2 \%)$ \\
\hline E & $10(20,8 \%)$ & $25(52,1 \%)$ \\
\hline
\end{tabular}




\section{Clinical Outcome (Frankle Score)}

The table above shown the distribution of patients both preoperatively and postoperatively based on Frankle score. From 48 patients, pre-operatively, there were 6 patients $(12.5 \%)$ with Frankle A score; 6 patients (12.5\%) with Frankle B score; 11 patients (22.9\%) with Frankle C score; 15 patients $(31.3 \%)$ with Frankle D score; and 10 patients $(20.8 \%)$ with Frankle E score. Meanwhile post-operatively, the number of patients with Frankle A, B, C, D, and E were 3 patients (6.2\%); 3 patients (6.2\%); 4 patients (8.3\%); 13 patients (34.2\%); and 25 patients $(52.1 \%)$ respectively.

\section{Discussion}

ODI is a measuring tool that contains a list of questions or questionnaires designed to provide information on how much the level of disability of low back pain (LPB) in carrying out daily activities. ${ }^{5,21}$ ODI divides the level of disability experienced by patients into minimal disability (0-20\%), moderate disability (21$40 \%$ ), severe disability (41-60\%), very severe disability (61-80\%), and highest disability (81-100\%), where the patient cannot do any activity. ${ }^{22,23,24}$

SF-36 is an assessment package of quality of life that is easy, coherent, and generic. ${ }^{25}$ Whereas the VAS is an instrument used to assess pain intensity using a $10 \mathrm{~cm}$ line table with a reading scale of $0-100 \mathrm{~mm}$ with a range of no pain $(0-10 \mathrm{~mm})$, mild pain $(10-30 \mathrm{~mm})$, moderate pain $(30-70 \mathrm{~mm})$, severe pain $(70-90$ $\mathrm{mm})$, and very severe pain $(90-100 \mathrm{~mm}) .^{26,27}$

Based on the characteristics of patients in this study where the average age was between 30-40 years, it was supported by the study of Hao et al where the average patient who suffered thoracolumbar injury was 3040 years old. In this study, patients with thoracal, thoracolumbar and lumbar injuries who underwent surgery experienced significant improvements in quality of life. ${ }^{28,29,30}$ This is indicated by the significant difference in ODI, VAS, and SF-36 scores before and after surgery. This is also supported by a significant p-value $(<0.05)$. ODI values decreased postoperatively with posterior instrumentation measures, as well as SF-36 values. The results of this study were consistent with other studies conducted by Hao et al, which showed that there was an improvement in the quality of life of patients after surgery.

\section{Conclusion}

From the results of the statistical analysis test on the outcome of the clinical function of patients with spinal cord injuries of the thoracic, thoracolumbar and lumbar regions who undergoes posterior instrumentation and assessed with SF-36, ODI, and VAS, there are significant improvements in patient's quality of life based on the clinical outcomes. This is indicated by the p-value $=0.001(<0.005)$.

We hope that further study could compare different techniques to see the post-operative clinical outcomes and to conduct periodic follow-up and compare it with non-operative treatment.

\section{References}

1. Kaveh Haddadi, Farzaneh Yosefzadeh, 2016, Epidemiology of Traumatic Spinal Injury in North of Iran: A Cross-Sectional Study, IrJNS.2015;1(4): 11-14

2. World Health Organization 2013, EpidemologyOf the Thoracolumbar Fracture and its Characteristic, WHO jurnal, 2017. USA.

3. Martini f.h., welch k. Fundamentals of anantomy and physiology. $5^{\text {th }}$ ed. Newjersey: upper saddle river, 2001: $132,151 \mathrm{PG}$

4. Anatomi fungsional vertebra, accessed on 24 January, available from http://fisiosby.com/anatomifungsional-vertebra

5. Schreiber D. Spinal Cord Inuries, eMedicine Journal, April, 2002

6. Braken MB. Steroid For Acute Spinal Cord Injury (Cochrane Review): Cochrane Library, Issue 3, 2002

7. The Danger of Spinal Cord Injury.2009.accessed on 2019 Mar 26, available from:http://www.nutritionalsupplementproduct.com/1381/spinal-cord-injury/ 
8. Hurlbert RJ. Methylprednisolone for Acute Spinal Cord Injury: An Inappropriate Standard of Care. J Neurosurg (Spine). 2000;93: 1-7

9. Adams RD, Victor M, Ropper AH. Disease of Spinal Cord in Principles of Neurology, $7^{\text {th }}$ ed. McGrawHill, New York, 2001.

10. Trauma Vertebra. 2018. accessed on 2019 Mar 26, available from: http://www.maitriseorthop.com/korpusmaitri/orthopaedic/102_duquennoy/pec_trauma_med_us.shtml

11. Anil K jain, Sudhir Kumar: Neglected Musculoskeletal Injuries, jaypee brother medical publisher, New Delhi 2010, 437:142-160.

12. Kavin Khatri, Kamran Farooque, Vijay Sharma, Babita Gupta, Shivanand Gamanagatti, 2016, Neglected Thoraco Lumbar Traumatik Spine Injuries, Asian Spine J 2016;10(4):678-684.

13. Dilip K. Sengupta, MD, Dr. Med, Neglected Spinal Injuries, clinical orthopaedics and related research, Number 431, pp. 93-103

14. Goodrich J Allan MD, Goldsten Jeffrey A, September 2016, Chance fraktur,

15. Vaccaro AR, Oner C, Kepler CK, et al; AOSpine Spinal Cord Injury \& Trauma Knowledge Forum. AOSpine thoracolumbar spine injury classification system: fracture description, neurological status, and key modifiers. Spine 2013;38:2028-2037.

16. Reinhold M, Audigé L, Schnake KJ, Bellabarba C, Dai LY, Oner FC. AO spine injury classi cation system: a revision proposal for the thoracic and lumbar spine. Eur Spine J 2013;22:2184-2201.

17. Patel AA, Vaccaro AR. Thoracolumbar spine trauma classi cation. J Am Acad Orthop Surg 2010;18: 63-71.

18. Vaccaro AR, Lehman RA Jr, Hurlbert RJ, et al. A new classi cation of thoracolumbar injuries: the impor- tance of injury morphology, the integrity of the po- sterior ligamentous complex, and neurologic status. Spine 2005;30:2325-2333.

19. Heinzelmann $M$, Wanner Guido A. Thoracolumbar Spinal Injuries. $2^{\text {nd }}$ Volume.Boos, N. Springer,2008.1165

20. Thompson Jon C. Netter's Concise Orthopaedic Anatomy. $2^{\text {nd }}$.ed. Craig John A.Philadelphia: Saunders Elsevier, 2010.

21. Rockwood\&Green's,2001. Fractures in adult. $8^{\text {th }}$.ed. Philadelphia: Wolters Kluwer, 2015. 1651p.

22. Rajasekaran S, Kanna RM, Shetty AP. Management of thoracolumbar spine trauma: An overview. Indian journal of orthopaedics. 2015 jan;49(1):72.

23. Maccauro G, Spinelli MS, Mauro S. Physiopathology of Spine Metastasis. International Journal of Surgical Oncology.2011 June 1; 2011:1.

24. Egol Kenneth A, Koval Kenneth J. Handbook of Fractures. $4^{\text {th }}$. Ed. Zuckerman Joseph D. Philadelphia: Lippincott Williams \& Wilkins, 2010. 119p.

25. Brunette D, Rockswold G. Neurologic Recovery Following Rapid Spinal Realignment for Complete Cervical Spinal Cord Injury. J Trauma 1987;27:445-447.

26. Fenstermaker RA. Acute Neurologic Management of the Patient with Spinal Cord Injury. Urologic Clinic of North America 1993;20:413-421.

27. Podolsky S.et al. Neurologic Complication Following Immobilization of Cervical Spine Fracture in a Patient with AnkylosingSpondilytis. Ann Emerg Med 1983;12:578-580.

28. Khurana B, Sheehan SE, Sodickson A. Traumatic Thoracolumbar Spine Injuries: What the Spine Surgeon Wants to Know. RSNA. 2013 Nov 1;33(7):2034.

29. Fraktur Vertebra.2009. accessed on 2019 Mar 26, available from: http://bedahumumfkunram.blogspot.com/2009/02/fraktur-vertebra.html

30. Pengukuran Kuantitas Nyeri. Universitas Hasanudin. Available from : med.unhas.ac.id/fisioterapi/wpcontent. Accessed October 12, 2017. 
For all your Research Requirements, log on to www.sphinxsai.com

International Journal of PharmTech Research,

International Journal of ChemTech Research, 